\title{
Composição Química e Energética de Amostras de Milho Submetidas a Diferentes Temperaturas de Secagem e Períodos de Armazenamento ${ }^{1}$
}

\author{
Débora Cristine de Oliveira Carvalho 2,3 , Luiz Fernando Teixeira Albino ${ }^{4}$, Horacio Santiago \\ Rostagno $^{4}$, Jean Eduardo de Oliveira ${ }^{2}$, José Geraldo de Vargas Júnior ${ }^{5}$, Rodrigo Santana \\ Toledo $^{2}$, Carlos Henrique Rocha Costa ${ }^{6}$, Sandra Regina Freitas Pinheiro ${ }^{7}$, Renata Mara de Souza ${ }^{7}$
}

\begin{abstract}
RESUMO - O objetivo do experimento foi determinar a composição química, energia bruta, energia metabolizável aparente (EMA) e energia metabolizável aparente corrigida (EMAn) de amostras de milho submetidas a diferentes temperaturas de secagem (temperatura ambiente e secagem artificial com temperaturas de 80,100 e $\left.120^{\circ} \mathrm{C}\right)$ e a diferentes períodos de armazenamento ( $0,60,120$ e 180 dias $)$. Para determinar os valores de EMA e de EMAn, foi utilizado o método tradicional de coleta total de excretas com pintos machos, Avian Farm, de 21 a 30 dias de idade. Utilizou-se um esquema fatorial 4 x 4 (quatro temperaturas de secagem e quatro períodos de armazenamento), em um delineamento inteiramente casualizado com sete repetições por tratamento e sete aves por unidade experimental. Cada amostra de milho substituiu em $40 \%$ da matéria natural, uma ração-referência. Foram realizadas análises de composição química e energia bruta de cada amostra de milho. Foi determinada também a energia bruta das excretas. A composição química e os valores de energia bruta $(\mathrm{kcal} / \mathrm{kg})$ das amostras de milho não foram significativamente influenciados pela temperatura de secagem e pelo tempo de armazenamento. Entretanto, os valores de EMA e de EMAn foram influenciados pela temperatura de secagem e pelo tempo de armazenamento, isoladamente. Foi observado efeito quadrático para temperatura de secagem, com maiores valores de EMA e EMAn do milho nas temperaturas de 49 e $50^{\circ} \mathrm{C}$, respectivamente, obtidos por equação de regressão. Para o tempo de armazenamento, observou-se efeito linear decrescente para os valores de EMA e de EMAn. Observou-se que a temperatura de secagem e o tempo de armazenamento dos grãos de milho reduziram os valores de EMA e de EMAn.
\end{abstract}

Palavras-chave: energia metabolizável aparente, energia metabolizável aparente corrigida, frangos de corte, milho, temperatura de secagem, tempo de armazenamento

\section{Chemical and Energy Composition of Corn Sample under Different Drying Temperature and Storage Periods}

\begin{abstract}
The objective of the experiment was to determine the chemical composition, crude energy, apparent metabolizable energy (AME) and corrected metabolizable energy (AMEn) from samples of corn submitted to different drying temperatures (environmental temperature and artificial drying with temperatures of 80,100 and $120^{\circ} \mathrm{C}$ ) and different storage periods $(0,60,120$ and 180 days). The total excreta collection method was used to determine the values of AME and AMEn, for Avian Farm birds, males, reared from 21 to 30 days of age. A completed randomized experimental design in a 4 x 4 factorial arrangement (drying temperature and storage period), with seven replicates per treatment and seven birds per experimental unity, was used. Each corn sample replaced $40 \%$ as fed of the reference diet. Chemical composition analysis and gross energy of each corn samples. The gross energy of excreta also was determined. Chemical composition and gross energy ( $\mathrm{kcal} / \mathrm{kg}$ ) were not affected by drying temperatures and storage periods. However, values for AME and AMEn were influenced by drying temperatures and by storage periods, separately. A quadratic effect for drying temperatures was observed, with higher values of AME e AMEn at 49 and $50^{\circ} \mathrm{C}$, respectively, obtained by regression equation. For storage periods it was observed a linear decrease effect. It was observed that the drying temperatures and the storage periods of corn reduced the values of AME and AMEn.
\end{abstract}

Key Words: apparent metabolizable energy, broiler chicken, corn, corrected apparent metabolizable energy, storage periods, temperature of drying

\footnotetext{
1 Parte da Tese de Mestrado do primeiro autor.

2 Estudante do curso de Pós-graduação em Zootecnia DZO/UFV - Viçosa - MG, CEP: 36570-000. (debacris@yahoo.com.br)

3 Bolsista do CAPES.

4 Professor do Departamento de Zootecnia da Universidade Federal de Viçosa. (lalbino@ufv.br; rostagno@ufv.br)

5 Zootecnista, DSc em Nutrição de Monogástricos. (jgvargas@pop.com.br)

6 Bolsista de Iniciação Científica da FAPEMIG.

7 Estudante de graduação - DZO/UFV. (sandrazoo@ig.com.br; renatazoo@ig.com.br)
} 


\section{Introdução}

A alimentação representa a maior parte dos custos na produção avícola; medidas para reduzir estes custos podem significar lucro para o setor. A utilização de matérias-primas de composição conhecida que atendam à exigência nutricional, com programas de alimentação adequados a custos mínimos, resulta em maior eficiência na produção.

Entre as matérias-primas que constituem uma ração, os grãos representam percentual elevado e, portanto, influenciam de forma significativa a qualidade final da ração. $\mathrm{O}$ milho constitui aproximadamente $60 \%$ de uma ração para frangos de corte, na qual contribui com $65 \%$ da energia metabolizável (EM) e $22 \%$ da proteína.

Vários alimentos têm sido submetidos a um processamento com altas temperaturas, a fim de se eliminar toxinas, destruir inibidores, tornando os nutrientes mais disponíveis para os animais. Hatfield \& Wilson (1972) observaram efeitos benéficos na tostagem de milho quando este foi fornecido para bovinos e suínos em terminação.

Em razão da preocupação com o desenvolvimento de fungos, decorrentes de alta umidade, os grãos de milho têm sido submetidos à secagem mais severa, tornando-se quebradiços e danificados, com os níveis de energia e proteína afetados, bem como de outros nutrientes. Entretanto, existem poucas informações sobre como estas frações danificadas podem afetar o valor nutritivo do milho. Dale (1994) observou que grãos quebrados possuem $90 \mathrm{kcal}$ de EM/kg a menos em relação aos grãos inteiros. $\mathrm{O}$ autor investigou a diferença de proteína nos dois tipos de grãos e não notou diferença entre conteúdo de proteína do grão inteiro em relação aos grãos quebrados.

Costa et al. (1976), trabalhando com suínos em terminação, observaram que o valor de energia metabolizável e a absorção de nitrogênio do milho, submetido a secagem com temperatura de $160^{\circ} \mathrm{C}$, foi significativamente menor em relação ao milho seco a temperaturas de 80 e $120^{\circ} \mathrm{C}$.

Uma das conseqüências das más condições de armazenamento (temperatura e umidade inadequadas) e da atividade fúngica é a redução do conteúdo de óleo dos grãos, que implica em redução do valor de EM do alimento. Segundo Krabbe (1995), a EM do milho pode ser depreciada de 5 a $25 \%$ em função do armazenamento inadequado.

Boa porcentagem do total de milho produzido no
Brasil é destinada à avicultura para produção de rações e, como este setor necessita da qualidade do grão de milho para assegurar competitividade, a garantia de que o processamento adotado não prejudicou o valor nutritivo do milho faz-se necessária.

Diante do exposto, este trabalho foi desenvolvido com o objetivo de determinar a composição química e os valores de EMA e de EMAn de amostras de milho submetidas à secagem natural (temperatura ambiente) e secagem artificial (temperaturas de 80 , 100 e $\left.120^{\circ} \mathrm{C}\right)$ e armazenadas por diferentes períodos $(0,60,120$ e 180 dias $)$.

\section{Material e Métodos}

A pesquisa foi desenvolvida em duas etapas, sendo que, na primeira etapa, foram realizadas as secagens de sete cargas completas do secador KW-25, com uma das temperaturas estabelecidas $(80,100 \mathrm{e}$ $120^{\circ} \mathrm{C}$ ). Realizadas as secagens e pesagens, os grãos de milho foram armazenados durante 180 dias em silos metálicos. Durante esse período de armazenamento, amostragens para avaliação da qualidade dos grãos foram realizadas aos $0,60,120$ e 180 dias. No recebimento do produto, foi retirada uma quantidade de grãos para secagem à sombra, em local ventilado e, posteriormente, submetida às mesmas condições de armazenagem e avaliações que as amostras submetidas à secagem artificial.

As secagens natural e artificial foram concluídas quando o teor de umidade do milho atingiu $13 \%$, para evitar o desenvolvimento de fungos durante o armazenamento.

As amostras foram utilizadas para avaliação física dos grãos, que compreendeu análises de porcentagem de grãos quebrados, suscetibilidade dos grãos à quebra, perda de peso dos grãos, teor de umidade dos grãos, grau de infestação, análise de micotoxinas dos grãos e avaliação biológica. A avaliação física faz parte do trabalho de Campos (2001).

Na segunda etapa, foram conduzidos quatro ensaios biológicos nos períodos de 04/06 a 13/06/2001, 03/08 a 12/08/2001, 01/10 a 10/10/2001, e 30/11 a 09/12/2001, correspondendo, respectivamente, aos períodos de armazenamento. Nesta etapa, foram determinados os valores de EMA das amostras de milho submetidas às secagens natural (temperatura ambiente) e artificial (temperaturas de 80, 100 e $120^{\circ} \mathrm{C}$ ), todas com teor de umidade de $13 \%$ e armazenadas por diferentes períodos $(0,60,120$ e 180

R. Bras. Zootec., v.33, n.2, p.358-364, 2004 
dias). Utilizou-se o método tradicional de coleta total de excretas, utilizando 245 pintos de corte machos da linhagem Avian Farms, para cada ensaio biológico. As aves foram criadas em círculo de proteção, em galpão de alvenaria, até 21 dias de idade e alimentadas com ração inicial de frangos de corte à base de milho e farelo de soja. No vigésimo primeiro dia, as aves foram pesadas e transferidas para baterias metálicas dispostas em uma sala de $80 \mathrm{~m}^{2}$, com 4,0 m de pé direito e janelas de vidro, recebendo luz natural e, ou, artificial, por 24 horas.

O período experimental para cada ensaio biológico teve duração de dez dias, sendo cinco dias para adaptação das aves à ração e às instalações e cinco dias para coleta das excretas. Utilizou-se esquema fatorial $4 \times 4$ (quatro temperaturas de secagem e quatro períodos de armazenamento), com sete repetições por tratamento e sete aves por unidade experimental, no delineamento inteiramente casualizado. $\mathrm{O}$ alimento teste substituiu em $40 \%$ a ração-referência (Tabela 1). A ração-referência foi calculada de forma a atender às exigências estabelecidas por Rostagno (2000).

A temperatura média no interior da sala, registrada durante os quatro ensaios biológicos, foi de $21,5 \pm 1,0^{\circ} \mathrm{C}$.

Durante os dez dias de período experimental, as aves receberam ração e água à vontade. A coleta total das excretas, iniciada após o período de adaptação, foi realizada duas vezes ao dia, às 8 e $17 \mathrm{~h}$, para evitar fermentação. As bandejas foram revestidas com plástico para facilitar a coleta e evitar perdas do material.

Ao final de cada coleta, as excretas foram acondicionadas em sacos plásticos, previamente identificados, e colocadas em freezer até o final do período experimental. Posteriormente, foram descongeladas, pesadas e homogeneizadas, sendo retiradas alíquotas de cada repetição para pré-secagem e colocadas em estufa com ventilação forçada, à temperatura de $55^{\circ} \mathrm{C}$, por 72 horas. As amostras de excretas foram, então, moídas e submetidas às análises de matéria seca (MS), nitrogênio (N) e energia bruta (EB), segundo as metodologias descritas por Silva (1990).

Foram feitas análises de MS, EB e N das rações e das excretas, bem como de MS, EB, proteína bruta $(\mathrm{PB})$, extrato etéreo (EE), matéria mineral (MM), cálcio $(\mathrm{Ca})$ e fósforo $(\mathrm{P})$ das amostras de milho.

Ao término do período experimental, foram determinados o consumo de ração e a quantidade total de excretas.
Tabela 1 - Composição porcentual e calculada da ração referência

Table 1 - Percentage and calculated composition of the reference diet

\begin{tabular}{|c|c|}
\hline $\begin{array}{l}\text { Ingredientes } \\
\text { Ingredients }\end{array}$ & $\%$ \\
\hline Milho & 46,56 \\
\hline Corn & \\
\hline Farelo de soja & 46,01 \\
\hline Soybean meal & \\
\hline Fosfato bicálcico & 1,76 \\
\hline Dicalcium phosphate & \\
\hline Óleo de soja & 3,79 \\
\hline $\begin{array}{l}\text { Soybean oil } \\
\text { Calcário }\end{array}$ & 1,13 \\
\hline $\begin{array}{l}\text { Limestone } \\
\text { Sal }\end{array}$ & 0,39 \\
\hline $\begin{array}{l}\text { Salt } \\
\text { DL-Metionina (99\%) }\end{array}$ & 0,09 \\
\hline $\begin{array}{l}\text { DL-Methionine } \\
\text { Suplemento vitamínico } 1\end{array}$ & 0,08 \\
\hline $\begin{array}{l}\text { Vitamin supplement }{ }^{1} \\
\text { Suplemento mineral }^{2} \\
\text { Mineral supplement }^{2}\end{array}$ & 0,05 \\
\hline $\begin{array}{l}\text { Virginiamicina } \\
\text { Virginiamycin }^{3}\end{array}$ & 0,003 \\
\hline Cloreto de colina $(60 \%)$ & 0,10 \\
\hline $\begin{array}{l}\text { Choline chlorine } \\
\text { Anticoccidiano }\end{array}$ & 0,025 \\
\hline $\begin{array}{l}\text { Anticocidial }^{4} \\
\text { Antioxidante (BHT) } \\
\text { Antioxidant }\end{array}$ & 0,01 \\
\hline TOTAL & 100,00 \\
\hline
\end{tabular}

Composição calculada

Calculated composition

Energia metabolizável (kcal/kg)

Metabolizable energy

Proteína bruta (\%)

Crude protein

Metionina (\%)

Methionine

Metionina + cistina $(\%)$

$2.950,0(2.915,0)^{5}$

Methionine + cystine

Lisina (\%)

Lysine

Cálcio (\%)

Calcium

Fósforo disponível (\%)

Available phosphorus

Sódio (\%)

$25,0(23,5)^{5}$

Sodium

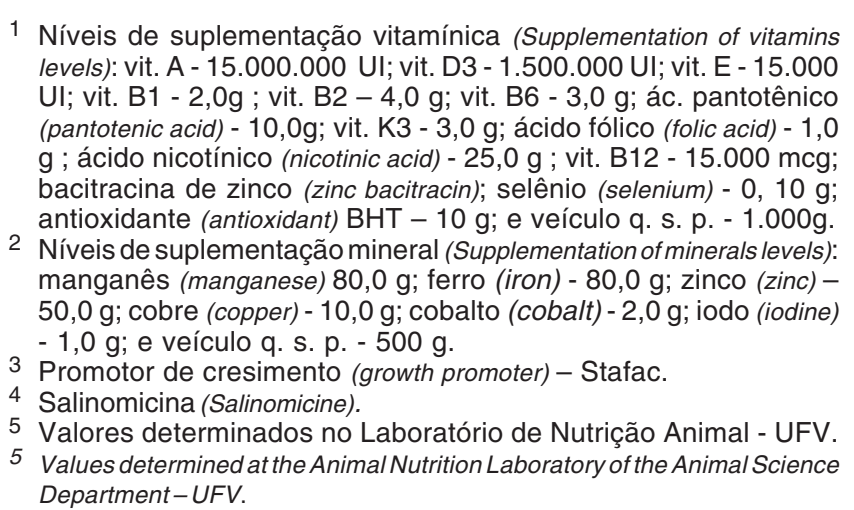


Com base nos resultados das análises bromatológicas das rações, das amostras de milho e das excretas, foram calculados os valores de EMA e de EMAn, usando as equações proposta por Matterson et al. (1965).

Os dados obtidos foram submetidos à análise de variância e metodologia de regressão superfície resposta utilizando o programa SAEG (Sistemas para Análises Estatísticas e Genéticas, desenvolvido na Universidade Federal de Viçosa -UFV 1999).

\section{Resultados e Discussão}

\section{Composição química das amostras de milho}

Os valores de composição química e de EB das amostras de milho encontram-se na Tabela 2.

Não houve efeito da temperatura e do tempo de armazenamento $(\mathrm{P}>0,05)$ na composição química e nos valores de EB das amostras de milho submetidas aos diferentes processamentos. Resultados semelhantes foram obtidos por Hathaway et al. (1952), Gausman et al. (1952), Cabell et al. (1958), Sullivan et al. (1973) e Costa et al. (1976 e 1977b).

As amostras de milho apresentaram, em média, $8,52 \%$ de $\mathrm{PB}$, na matéria natural. Os valores encontrados estão de acordo com os citados na literatura
(NRC, 1994, Rostagno et al., 2000). Os resultados obtidos de MS foram inferiores aos citados por NRC (1994) e por Rostagno et al. (2000). Tal ocorrência pode ser atribuída ao tipo de secagem a que os milhos foram submetidos, uma vez que todas amostras foram secas até atingirem $13 \%$ de umidade.

Os valores de extrato etéreo (EE) encontrados foram superiores aos citados na literatura. Os resultados de composição química obtida neste trabalho apresentam algumas diferenças em relação à composição química de algumas variedades de milho citada na literatura (NRC, 1994; Rostagno, 2000), evidenciando as diferenças existentes entre o mesmo alimento.

Análise física dos grãos de milho

Campos (2001) observou aumento na porcentagem de grãos quebrados e na perda de peso e maior susceptibilidade à quebra, à medida que aumentaram a temperatura de secagem e o tempo de armazenamento.

Valores de energia metabolizável aparente e de energia metabolizável aparente corrigida do milho

Os valores de EMA e EMAn são apresentados nas Tabelas 3 e 4 , respectivamente.

Observou-se efeito quadrático $(\mathrm{P}<0,05)$ para os valores de EMA e de EMAn com o aumento da temperatura de secagem. Os maiores valores de

Tabela 2 - Valores médios da composição química e energética das amostras de milho, expressos na matéria natural, de acordo com a temperatura de secagem e o período de armazenamento ${ }^{1}$

Table 2 - Average values of the chemical and energy composition of the corn samples, expressed in the natural matter, according to the drying temperature and the storage period

\begin{tabular}{|c|c|c|c|c|c|c|c|c|c|c|c|c|c|c|c|c|}
\hline & \multicolumn{4}{|c|}{$\begin{array}{l}\text { Não armazenado } \\
\text { Not stored }\end{array}$} & \multicolumn{4}{|c|}{$\begin{array}{l}\text { Armazenado por } 60 \text { dias } \\
\text { Stored by } 60 \text { days }\end{array}$} & \multicolumn{4}{|c|}{$\begin{array}{l}\text { Armazenado por } 120 \text { dias } \\
\text { Stored by } 120 \text { days }\end{array}$} & \multicolumn{4}{|c|}{$\begin{array}{l}\text { Armazenado por } 180 \text { dias } \\
\text { Stored by } 180 \text { days }\end{array}$} \\
\hline & $\mathrm{TA}^{2}$ & $80^{\circ} \mathrm{C}$ & $100^{\circ} \mathrm{C}$ & $120^{\circ} \mathrm{C}$ & $\mathrm{TA}^{2}$ & $80^{\circ} \mathrm{C}$ & $100^{\circ} \mathrm{C}$ & $120^{\circ} \mathrm{C}$ & $\mathrm{TA}^{2}$ & $80^{\circ} \mathrm{C}$ & $100^{\circ} \mathrm{C}$ & $120^{\circ} \mathrm{C}$ & $\mathrm{TA}^{2}$ & $80^{\circ} \mathrm{C}$ & $100^{\circ} \mathrm{C}$ & $120^{\circ} \mathrm{C}$ \\
\hline $\operatorname{MS}(\%)$ & 85,23 & 84,98 & 84,81 & 84,92 & 85,27 & 85,16 & 84,96 & 85,24 & 86,91 & 86,31 & 86,21 & 86,55 & 86,61 & 86,42 & 86,39 & 86,45 \\
\hline $\mathrm{PB}(\%)$ & 8,71 & 8,37 & 8,81 & 8,52 & 8,56 & 8,44 & 8,48 & 8,49 & 8,75 & 8,47 & 8,60 & 8,44 & 8,38 & 8,17 & 8,56 & 8,62 \\
\hline $\mathrm{EE}(\%)$ & 5,07 & 4,39 & 5,12 & 4,63 & 4,99 & 4,40 & 4,45 & 4,78 & 4,40 & 4,73 & 4,63 & 4,98 & 4,95 & 5,10 & 4,93 & 5,09 \\
\hline $\mathrm{FB}(\%)$ & 2,21 & 1,97 & 1,85 & 1,97 & 2,20 & 2,03 & 1,98 & 2,15 & 2,04 & 1,99 & 2,15 & 2,00 & 2,13 & 2,19 & 1,96 & 2,01 \\
\hline MM (\%) & 1,25 & 1,23 & 1,33 & 1,25 & 1,22 & 1,26 & 1,230 & 1,24 & 1,26 & 1,27 & 1,23 & 1,20 & 1,22 & 1,22 & 1,24 & 1,25 \\
\hline $\mathrm{Ca}(\%)$ & 0,02 & 0,03 & 0,02 & 0,02 & 0,02 & 0,02 & 0,02 & 0,02 & 0,02 & 0,02 & 0,02 & 0,02 & 0,02 & 0,03 & 0,02 & 0,02 \\
\hline $\mathrm{P}(\%)$ & 0,23 & 0,22 & 0,25 & 0,25 & 0,24 & 0,23 & 0,23 & 0,25 & 0,26 & 0,26 & 0,25 & 0,26 & 0,23 & 0,25 & 0,27 & 0,26 \\
\hline $\mathrm{EB}^{3}$ & 3.993 & 4.001 & 3.948 & 3.942 & 3.977 & 3.989 & 3.900 & 3.952 & 3.958 & 3.950 & 3.937 & 3.930 & 3.969 & 3.974 & 3.970 & 3.958 \\
\hline
\end{tabular}

Análises realizadas no Laboratório de Nutrição Animal de Departamento de Zootecnia - UFV.

Analyses performed at the Animal Nutrition Laboratory of the Animal Science Department - UFV.

MS - matéria seca (dry matter), PB - proteína bruta (crude protein), EE - extrato etéreo (ether extract), FB - fibra bruta (crude fiber), MM - matéria

mineral (mineral matter), Ca - cálcio (calcium), P - fósforo (phosphorus), EB - energia bruta (gross energy).

1 Não houve efeito significativo $(P>0,05)$ para todos os parâmetros avaliados.

1 There was no significant effect $(P>$.05) for all the parameters.

2 TA - Milho seco à temperatura ambiente (temperatura média de $27^{\circ} \mathrm{C}$ ).

2 Dry corn to the environment temperature (average temperature of $27^{\circ} \mathrm{C}$ ).

3 Energia bruta em $\mathrm{kcal} / \mathrm{kg}$.

3 Gross energy in $\mathrm{kcal} / \mathrm{kg}$.

R. Bras. Zootec., v.33, n.2, p.358-364, 2004 
EMA e de EMAn foram obtidos pela equação de regressão (Tabela 5), a 49 e $50^{\circ} \mathrm{C}$, respectivamente. A razão para redução da EM do milho com a variação da temperatura de secagem não está bem esclarecida. Hathaway et al.(1952) relataram que o valor nutritivo do milho já é reduzido com temperaturas acima de $60^{\circ} \mathrm{C}$, porém esses autores trabalharam com ratos.

Vários estudos demonstraram que o tratamento térmico dos alimentos favorece a digestibilidade do alimento. O milho é um ingrediente com alta porcentagem de amido, que apresenta boa digestibilidade e, dependendo do processamento a que é submetido, sua digestibilidade poderá ser melhorada ou piorada. A temperatura de secagem sob a qual o amido se torna mais digestível difere entre os diversos tipos de amido dos alimentos. Para o amido do milho, a temperatura de secagem recomendada situa-se entre $62 \mathrm{e}$ $75^{\circ} \mathrm{C}$ (Penfield et al., 1990).

Pela estimativa do ponto de máxima da temperatura de secagem (a redução da EMA dos grãos iniciou a $49^{\circ} \mathrm{C}$ ), pode-se inferir que, antes de atingir a temperatura de secagem que melhoraria a

Tabela 3 - Valores médios de energia metabolizável aparente (EMA) das amostras de milho, expressos na matéria seca, de acordo com a temperatura de secagem e tempo de armazenamento

Table 3 - Average values of apparent metabolic energy (EMA) of the corn samples, expressed in the dry matter, according to the drying temperature and time of storage

\begin{tabular}{|c|c|c|c|c|c|}
\hline \multicolumn{6}{|c|}{$\operatorname{EMA}(\mathrm{kcal} / \mathrm{kg})$} \\
\hline \multirow{3}{*}{$\begin{array}{c}\text { Temperatura de secagem } \\
\text { Drying temperature }\end{array}$} & \multirow{2}{*}{\multicolumn{4}{|c|}{$\begin{array}{c}\text { Tempo de armazenamento (dias) } \\
\text { Time of storage (days) }\end{array}$}} & \multirow[b]{3}{*}{$\begin{array}{l}\text { Média } \\
\text { Average }\end{array}$} \\
\hline & & & & & \\
\hline & 0 & 60 & 120 & 180 & \\
\hline Temperatura ambiente ${ }^{1}$ & 3.820 & 3.835 & 3.765 & 3.716 & 3.784 \\
\hline \multicolumn{6}{|l|}{ Environment temperature ${ }^{l}$} \\
\hline $80^{\circ} \mathrm{C}$ & 3.892 & 3.872 & 3.837 & 3.659 & 3.815 \\
\hline $100^{\circ} \mathrm{C}$ & 3.801 & 3.746 & 3.645 & 3.633 & 3.706 \\
\hline $120^{\circ} \mathrm{C}$ & 3.633 & 3.577 & 3.578 & 3.511 & 3.575 \\
\hline Média & 3.787 & 3.758 & 3.706 & 3.630 & 3.720 \\
\hline Average & & & & & \\
\hline
\end{tabular}

${ }^{1}$ Temperatura média de $27^{\circ} \mathrm{C}$.

${ }^{1}$ Average temperature of $27^{\circ} \mathrm{C}$.

Tabela 4 - Valores médios de energia metabolizável aparente corrigida (EMAn) das amostras de milho, expressos na matéria seca, de acordo com a temperatura de secagem e tempo de armazenamento

Table 4 - Average values of corrected apparent metabolic energy (EMA) of the corn samples, expressed in the dry matter, according to the drying temperature and time of storage

\begin{tabular}{cccccc}
\hline & \multicolumn{5}{c}{ EMAn (kcal/kg) } \\
\hline $\begin{array}{c}\text { Temperatura de secagem } \\
\text { Drying temperature }\end{array}$ & \multicolumn{4}{c}{$\begin{array}{c}\text { Tempo de armazenamento (dias) } \\
\text { Time of storage (days) }\end{array}$} \\
\cline { 2 - 5 } & 0 & 60 & 120 & 180 & $\begin{array}{c}\text { Média } \\
\text { Average }\end{array}$ \\
\hline $\begin{array}{c}\text { Temperatura ambiente } \\
\text { Environment temperature }\end{array}$ & 3.770 & 3.778 & 3.709 & 3.677 & 3.734 \\
$80^{\circ} \mathrm{C}$ & 3.850 & 3.814 & 3.781 & 3.624 & 3.767 \\
$100^{\circ} \mathrm{C}$ & 3.755 & 3.686 & 3.640 & 3.594 & 3.669 \\
$120^{\circ} \mathrm{C}$ & 3.595 & 3.536 & 3.530 & 3.488 & 3.537 \\
Média & 3.743 & 3.704 & 3.665 & 3.596 & 3.677 \\
Average & & & & & \\
\hline
\end{tabular}

\footnotetext{
${ }^{1}$ Temperatura média de $27^{\circ} \mathrm{C}$.

${ }^{1}$ Average temperature of $27^{\circ} \mathrm{C}$.
}

R. Bras. Zootec., v.33, n.2, p.358-364, 2004 
Tabela 5 - Equações de regressão ajustada e coeficiente de determinação $\left(R^{2}\right)$ da energia metabolizável aparente (EMA) e energia metabolizável aparente corrigida (EMAn) das amostras de milho, em função da temperatura de secagem ( $x$ ) e do tempo de armazenamento do milho (z) em $\mathrm{kcal} / \mathrm{kg}$

Table 5 - Adjusted regressions and coefficient of determination $\left(R^{2}\right)$ of the apparent metabolic energy (EMA) and corrected apparent metabolic energy (EMAn) of the corn samples, iaccording to the drying temperature $(x)$ and the corn storage time (z), Kcal/kg

\begin{tabular}{ccc}
\hline $\begin{array}{c}\text { Parâmetros } \\
\text { Parameters }\end{array}$ & $\begin{array}{c}\text { Equações de regressão } \\
\text { Regression equations }\end{array}$ & $\mathrm{R}^{2}$ \\
\hline EMA & $\hat{\mathrm{Y}}=3.772+0,0044537 * \mathrm{x}-0,0000453 * \mathrm{x}^{2}-0,0008519 * \mathrm{z}$ & 0,90 \\
EMAn & $\hat{\mathrm{Y}}=3.717+0,0044633 * \mathrm{x}-0,0000443 * \mathrm{x}^{2}-0,0008079 * \mathrm{z}$ & 0,89 \\
\hline
\end{tabular}

* Significativo a $5 \%$ de probabilidade pelo teste " $\mathrm{t}$ ".

* Significant, $5 \%$ probability by test " $t$ ".

digestibilidade do amido, com redução da viscosidade, houve reação que pode ter afetado a gelatinização. É possível que a gelatinização do amido tenha começado e, simultaneamente, pode ter ocorrido interação entre açúcar redutor e amino livre da proteína, caracterizando a reação de Maillard e, conseqüentemente reduzindo os valores de EM. Foi observada redução de 5\% nos valores de EMA e EMAn dos grãos submetidos à secagem artificial na temperatura de $120^{\circ} \mathrm{C}$ em relação aos submetidos à secagem natural $\left( \pm 27^{\circ} \mathrm{C}\right)$. No entanto, Costa et al. (1976), trabalhando com suínos, encontraram menores valores de EM, quando os grãos de milho foram secos a temperaturas acima de $120^{\circ} \mathrm{C}$.

$\mathrm{O}$ peso dos grãos diminuiu com o aumento da temperatura e com o tempo de armazenamento. Provavelmente, esta é uma das razões para a redução dos valores de EMA. Baidoo et al. (1991) estabeleceram relação entre a densidade do grão e os valores de EMA. Os autores observaram que o decréscimo de $20 \%$ da densidade do grão está associado à redução de 4,3\% no valor de EMA. Rostagno (1993) afirma que este valor não pode ser desconsiderado, uma vez que a porcentagem média de incorporação do milho nas rações de aves é de $62 \%$ e redução de 4\% no valor de EMA do milho corresponderá a $85 \mathrm{kcal} / \mathrm{kg}$ de ração, o que provocará menor peso final e piora na conversão alimentar de, aproximadamente, $3 \%$, o que não é desejável.

À medida que se aumentou o tempo de armazenamento das amostras de milho, observou-se efeito linear $(\mathrm{P}<0,05)$, com redução para os valores de EM. Com o aumento do tempo de armazenamento a deteriorização da matéria-prima é acelerada, principalmente se esta matéria-prima tiver sofrido algum dano. Observou-se aumento na porcentagem de grãos trincados com a secagem, tornando-os mais susceptíveis à quebra total subseqüente, que culminou com deteriorização durante o armazenamento.

\section{Conclusões}

Foram observadas reduções na EMA e EMAn do milho que chegaram a cerca de $300 \mathrm{kcal} / \mathrm{kg}$ com o aumento da temperatura de secagem e tempo de armazenamento, apesar de não terem sido identificadas alterações na energia bruta ou na análise proximal.

\section{Literatura Citada}

ALBINO, L.F.T. Sistemas de avaliação nutricional de alimentos e suas aplicações na formulação de rações para frangos de corte. Viçosa, MG: Universidade Federal de Viçosa, 1991. 141p. Tese (Doutorado em Zootecnia) - Universidade Federal de Viçosa, 1991.

BAIDOO, S.K.; SHIRES, A.; ROBBLEE, A.R. Effect of kernel density on the apparent and true metabolizable energy value of corn for chickens. Poultry Science, v.70, p.2102 - 2107, 1991.

CABELL, C.A.; DAVIS, R.E.; SAUL, R.A. Some effects of variation in drying temperature, heating time, air flow rates and moisture content on nutritive value of field shelled corn. Journal of Animal Science, v.17, p.1204, 1958.

CAMPOS, M.G. Avaliação da quebra técnica e da qualidade do milho a granel, em função da temperatura de secagem e do tempo de armazenamento. Viçosa, MG: Universidade Federal de Viçosa 2001. 103p. Tese (Doutorado em Engenharia Agrícola) - Universidade Federal de Viçosa, 2001.

COSTA, P.M.A.; JENSEN, A.H.; HARMON, B.G.E. et al. The effects of roasting and temperatures on the nutritive value of e corn for swine. Journal of Animal Science, v.42, n.2, 1976.

COSTA, P.M.A.; JENSEN, A.H.; HARMON, B.G. et al. Effects of roasting and roasting temperatures on the nutritive value of high-moisture corn for swine. Journal of Animal Science, v.44, n.2, 1977b.

DALE, N. Efeito da qualidade no valor nutritivo do milho. In:

R. Bras. Zootec., v.33, n.2, p.358-364, 2004 
CONFERÊNCIA APINCO DE CIÊNCIA E TECNOLOGIA AVÍCOLAS, 1994, Campinas. Anais... Campinas: FACTA, 1994. p.67-72.

GAUSMAN, H.W.; RAMSER, J.H.; DUNGAN, G.H. et al. Some effects of artificial drying of corn grain. Plant Physiology, v.27, p.794, 1952.

HATFIELD, E.E.; WILSON, W.M.D. Effect of drying temperature and heat treatment on the nutritive value of corn. In: Effect of processing on the nutritional value of feeds. Washington, D.C.: National Academy of Sciences, 1972.

HATHAWAY, I.L.; YOUNG, F.D.; KIESSELBACH, T.A.The effect of drying temperature upon the nutritive value and commercial grade of corn. Journal of Animal Science, v.11, p.430, 1952.

KRABBE, E.L.; JUCHEM, S.; MACIEL, J.E.S. et al. Efeito das condições de armazenamento de grãos de milho da energia metabolizável aparente para frangos de corte criados com dietas de diferentes qualidades. In: CONFERÊNCIA APINCO DE CIÊNCIA E TECNOLOGIA AVÍCOLAS, 1995, Campinas. Anais... Campinas: FACTA, 1995. p.9-10.

MATTERSON, L.D.; POTTER, L.M.; STUTZ, M.W. et al. The metabolizable energy of feed ingredients for chickens. University of Connecticut Storrs. Agricultural Experiment Station Research Report, v.11, 11p. 1965.

NATIONAL RESEARCH COUNCIL - NRC. Nutrient requirements of Poultry. 9.ed. Washington, D.C.: National Academy Press, 1994. 155p.

PENFIELD, M.P.; CAMPBELL, A.M. Experimental food science. 3.ed. The University of Tennesse, Knoxville University of Nebraska, 1990. 386p.
ROSTAGNO, H.S. Disponibilidade de nutrientes em grãos de má qualidade. In: CONFERÊNCIA APINCO DE CIÊNCIA E TECNOlOGia AVÍCOLAS, 1993, Campinas. Anais... Campinas: FACTA, 1993. p.129 - 139.

ROSTAGNO, H.S.; ALBINO, L.F.T.; DONZELE, J.L. et al. Tabelas brasileiras para aves e suínos. Composição de alimentos e exigências nutricionais. Viçosa, MG: Universidade Federal de Viçosa, 2000. 141p.

SILVA, D.J. Análise de alimentos: métodos químicos e biológicos. 2.ed. Viçosa, MG: Universidade Federal de Viçosa, 1990. 165p.

SULLIVAN, J.E.; OWENS, F.N.; SHOCKEY, B.J. Corn roasting temperature e nutrient availability. Journal of Animal Science, v.37, p.291, 1973. (Abstr)

UNIVERSIDADE FEDERAL DE VIÇOSA - UFV. SAEG Sistema de análises estatísticas e genéticas. Versão 8.0.Viçosa, MG: 1999. 59p. (Manual do usuário).

Recebido em: 10/09/02

Aceito em: 01/08/03 